\title{
Uncertainty in consultations about genetic testing for cancer: an explorative observational study
}

Niki M. Medendorp ${ }^{1,2,3^{*}}$, Marij A. Hillen ${ }^{1,2,3}$, Laxsini Murugesu' ${ }^{1}$, Cora M. Aalfs ${ }^{4,5}$, Anne M.

Stiggelbout $^{6}$, Ellen M.A. Smets ${ }^{1,2,3}$.

1. Department of Medical Psychology - Academic Medical Centre / University of Amsterdam, Amsterdam, The Netherlands

2. Amsterdam Public Health research institute, Amsterdam, The Netherlands

3. Cancer Centre Amsterdam, Amsterdam, The Netherlands

4. Department of Clinical Genetics - Academic Medical Centre / University of Amsterdam, Amsterdam, The Netherlands

5. Department of Clinical Genetics - VU University Medical Centre, Amsterdam, The Netherlands

6. Department of Medical Decision Making - Leiden University Medical Centre, Leiden, The Netherlands

*Corresponding author: Niki M. Medendorp | Academic Medical Centre, University of Amsterdam, Department of Medical Psychology | P.O. Box 22700, 1100 DE Amsterdam, The Netherlands | E-mail: n.m.medendorp@amc.uva.nl | Tel: +31-20-5667112 


\section{Abstract}

Objective: Persons seeking cancer genetic counseling mainly aim to obtain information and certainty about their medical situation. However, the information that counselees receive often involves many uncertainties. To develop strategies to enable optimal communication about uncertainties, the spectrum of uncertainty expressed within cancer genetic counseling needs to be established. This study aimed to gain insight into the uncertainties verbally expressed by counselors and counselees.

Methods: Twenty-five consultations were audiotaped, transcribed and qualitatively analyzed. A coding scheme identifying all uncertainties was developed parallel to the coding of the transcripts. Results: Several uncertainties were identified varying in their source (i.e. the cause of uncertainty) and the issues involved (i.e. the topic to which uncertainty pertained). The main sources of uncertainty were the unpredictability of the future and a lack of knowledge. Counselees also expressed uncertainty related to the amount and complexity of the information. Counselors expressed uncertainties mainly related to scientific issues, whereas counselees' uncertainty mainly related to personal and practical issues.

Conclusion: A wide range of uncertainties was expressed by both groups. Counselors differ from counselees in the degree and types of uncertainty they express.

Practice implications: Counselors should address scientific uncertainties during genetic counseling to increase awareness and understanding in counselees.

Keywords: uncertainty; cancer genetic counseling; counselor; counselee. 


\section{Introduction}

Cancer genetic counseling is the process of helping people understand and adapt to the medical, psychological and familial implications of genetic contributions to cancer. It usually involves the interpretation of family and medical histories, education about inheritance, testing and prevention, promotion of informed choices, and adaptation to the risk or condition [1]. The main reasons for counselees to seek cancer genetic counseling are to i) obtain information, ii) make decisions, and iii) reduce uncertainty about their medical situation [2-4]. However, genetic counseling does not necessarily resolve uncertainty, as the information provided by counselors will involve several uncertainties. Counseling might introduce new forms of uncertainty to counselees, e.g. concerning possible predispositions for diseases other than that for which counseling was sought for $[1,5,6]$.

Although several definitions exist [7-11], 'uncertainty' can broadly be defined as the subjective perception of ignorance, referring to a self-awareness of existing incomplete knowledge of some aspect of the world [7]. For example, it includes perceptions of indeterminacy, unreliability and feelings of doubt. Genetic counseling is a setting that involves many uncertainties. These uncertainties can include risks, which are also defined as probabilities, i.e., the likelihood of a future event [7]. Specific examples of risks applying to genetic counseling are the risk of carrying or inheriting a mutation, and the risk of an incidental finding, i.e., a genetic variant that has not been specifically searched for, but which might have clinical importance for the patient $[12,13]$. In addition to risks, limitations related to the quality and/or reliability of the information (e.g. ambiguity) are also part of uncertainty [7]. Two examples of ambiguity in genetic counseling are i) uncertainty about the association between a genetic variant and a certain disease, and ii) uncertainty about the cause of death of family members [14].

It is generally considered beneficial for counselors to openly communicate about such uncertainties during genetic counseling, as this may enhance counselees' confidence in their counselor and improve their mutual relationship $[15,16]$. Explicitly discussing uncertainties is also considered ethically justified, as this enhances counselees' autonomy and enables informed decision-making $[8,17]$. Moreover, discussing uncertainties may help counselees to have a more realistic expectation about 
their medical condition $[15,16]$. Nevertheless, communicating about uncertainty also has potential drawbacks. Awareness of the uncertainties associated with genetic testing might overwhelm counselees, cause them to worry, and can even impair their ability to make well-informed decisions regarding genetic testing $[8,18]$. Considering these potential drawbacks, not all uncertainties may be openly discussed by counselors during genetic counseling. In addition, some uncertainties may only be expressed non-verbally. Studies showed that non-verbal indicators may convey uncertainty as powerfully as verbal expressions $[19,20]$.

The ways in which awareness of uncertainty affects counselees may depend on what and how counselors discuss this [8]. Ideally, uncertainty is introduced by counselors in a way that enables counselees to make better-informed decisions (e.g. whether or not to perform a genetic test), without causing harmful psychological consequences [7]._However, it is not yet established i) which strategies are most effective when communicating about uncertainty, and ii) whether and how counselors should be supported to optimally convey issues related to uncertainty.

To develop strategies for optimal communication about uncertainty, it is necessary to first establish the extent of the spectrum of uncertainties expressed within cancer genetic counseling. Studies on uncertainty in various healthcare settings have resulted in multiple classifications of uncertainty $[9,21$, 22]. Building on these classifications, Han et al. developed a theoretical framework to classify medical uncertainty in general [7] and in the genetic setting in particular [14]. In their framework, the authors distinguished between sources (i.e., the causes of uncertainty), issues (i.e., the specific situation to which uncertainty pertains) and locus (i.e., the person(s) in which the uncertainty resides). Using the taxonomy of Han et al., Howard and Iwarsson [23] provided an overview of uncertainties relevant to whole genome sequencing. However, few empirical data are available on the expression of uncertainty in the healthcare setting. One study identified variations between physicians in their expressions of uncertainty [24] and another study reported that probability was the most prevalent source of uncertainty discussed during breast cancer consultations and that, overall, patients struggled with understanding uncertainty [11].

To our knowledge, no empirical evidence is available within the context of genetic counseling on to what extent theoretical frameworks of uncertainty apply to the clinical genetic setting. Therefore, 
this explorative study aims to provide insight into the range of all verbal expressions of uncertainty by counselors and counselees during initial cancer genetic counseling consultations.

\section{Methods}

\subsection{Design}

This study comprised an observational qualitative analysis of audiotaped initial cancer genetic consultations. The Medical Ethics Review Board of the Academic Medical Centre Amsterdam (The Netherlands) approved the protocol but waived the need for ethico-legal adjudication as this study was judged to have no serious impact on the participants.

\subsection{Participants and procedure}

\subsubsection{Counselors}

Counselors (including clinical geneticists, medical residents and genetic counselors) performing cancer genetic counseling were eligible for participation. Counselors were consecutively recruited from two tertiary referral centers in The Netherlands, informed about the study content and procedure, and asked for their participation by the researcher (N.M.). Counselors agreeing to participate signed an informed consent form and filled out a questionnaire regarding their gender, age, affiliation and function, and years of experience in genetic counseling.

\subsubsection{Counselees}

Counselees visiting one of the participating counselors and meeting the inclusion criteria were consecutively recruited. The inclusion criteria were aged $\geq 18$ years, visiting for initial cancer genetic counseling, and understanding adequate Dutch. Eligible counselees were informed about the study by their counselor at the start of their consultation. If they consented to participate, they signed an informed consent form after which the consultation was audiotaped. All counselees were informed about their right to withdraw from participation without any consequences. Following the consultation, counselors reported the counselees' gender, age and medical characteristics. The latter information included whether counselees were affected themselves and/or had a relative affected by cancer, the type and number of familial cancer, and whether a genetic test was ordered after the consultation. We 
estimated that data saturation (i.e., no new relevant information emerging) would be achieved within \pm 3 consecutive genetic consultations per counselor and ten counselors in total, including clinical geneticists, genetic counselors and residents $[25,26]$, i.e. a total of about 30 consultations. If required, there was a possibility to audiotape additional genetic consultations.

\subsection{Data analysis}

All recordings were transcribed verbatim and coded using MAXQDA software [27]. Data was analyzed using the constant comparative method [28]. This method is based on the principle of analyzing data in order to develop a theory [28]. Moreover, we used a combination of an inductive and a deductive approach. First, verbal expressions of uncertainty were coded inductively, i.e., the coding scheme was not pre-specified but developed parallel to the coding of the transcripts [29]. Two trained researchers (N.M. and M.A.), with backgrounds in psychology, independently coded the first transcript and developed a basic coding scheme. As a starting point, they agreed on coding all verbal expressions by counselors and counselees that they perceived as pertaining to some form of uncertainty, i.e., awareness of ignorance [7]. The resulting two basic coding schemes were discussed and consensus on one basic coding scheme was reached. Subsequently, the same researchers coded the next seven transcripts independently. After each transcript, codings were compared and discussed until consensus was reached. Additionally, the coding scheme was complemented and revised continuously, based on outcomes of the consensus meetings. Further coding showed that the verbal expressions of uncertainty differed strongly between counselors and counselees. After conferring with a senior researcher (E.S., with a background in psychology), it was decided to separate the coding schemes for both groups. Counselees were found to express uncertainty mainly in the form of questions, therefore, any question asked by counselees that related to uncertain information provided by the counselor, was labelled as a verbal expression of uncertainty, e.g. 'If it turns out that I carry a mutation, this doesn't necessarily mean that my children do too, right?' (46-year-old female, cancer patient). After eight transcripts, data saturation was achieved and the two coding schemes were considered to be comprehensive. 
The remaining seventeen transcripts were double-coded independently by two researchers (N.M. and L.M., the latter with a background in health sciences) and discrepancies were discussed with a third researcher (M.A.) until consensus was reached. When critically reviewing and thematically categorizing the comprehensive coding schemes, a distinction emerged between the provocation that caused the uncertainty, i.e., the source of uncertainty, and the content of the uncertain information, i.e., the issue to which uncertainty applies. This distinction is in line with the taxonomy of Han et al. [7]. Therefore, we continued our analysis more deductively, categorizing the uncertainties along their source (i.e., probability, ambiguity and complexity) and issue (i.e. scientific, practical and personal) [7] to identify distinct verbal expressions of uncertainty. Subsequently, the identified uncertainties were discussed among all six members of the research team, after which some were combined or adjusted. Finally, a definitive set of uncertainties was established for counselors and counselees separately.

\section{Results}

\subsection{Study sample}

Of the 10 counselors who were invited to participate and consented, one did not participate due to time constraints. Of the nine counselors, eight generated three audio-recordings each and one counselor generated one recording; resulting in a total of 25 audiotapes. One consultation involved the discussion of a multigene panel test, whereas the remainder involved single gene tests. The duration of the consultations ranged from $18-67 \min (\mathrm{M}=36)$.

All 25 counselees invited to participate agreed. In three cases there were no plans (yet) to perform genetic tests after the recorded consultation; reasons were no indication for a genetic predisposition $(\mathrm{n}=1)$, and a relative affected by cancer could be tested first $(\mathrm{n}=2)$. Table 1 presents the characteristics of both participant groups.

Table 1. Characteristics of the participating counselors and counselees.

\section{Table 1}

\subsection{Verbal expressions of uncertainty}


Uncertainty was expressed in all consultations by both counselors and counselees. To structure the results, the expressions of uncertainty by the counselors and counselees (i.e., the locus of uncertainty) are described separately according to their source and issue, shown in Fig. 1. All example quotations are displayed in Table 2, for counselors, and Table 3 for counselees.

Figure 1. Overview of loci, sources and issues of uncertainty identified in the current study

\section{Figure 1}

\subsubsection{Uncertainty expressed by counselors}

The first source of uncertainty expressed by counselors was related to future events that cannot be predicted. In line with Han et al. [7], we labelled this as probability. Counselors expressed probability about multiple issues, including the chance of carrying a mutation (Table 2, citation Ia), developing cancer (Ib), and inheriting a mutation (Ic). In a subset of the consultations, counselors additionally expressed the probabilities of encountering an incidental finding as a result of genetic testing (Id), and identifying a predisposition for a related disease (Ie).

In addition to probability, a second source of uncertainty among the verbal expressions of counselors was identified: uncertainty resulting from a lack of knowledge about a certain topic. Most uncertainties concerned a lack of knowledge at the scientific level (i.e., current unknowns in clinical genetics in general). One example is the inability to identify all mutations using currently available techniques (IIa). Other examples are the current inability to prevent or screen for cancer (IIb) and a lack of knowledge about the meaning and consequences of mutations (IIc).

Counselors also verbally expressed uncertainties resulting from a lack of knowledge at a personal level (i.e., the counselor's own uncertainty). These uncertain expressions were, however, relatively scarce and were primarily expressed regarding factual medical information (IIIa).

\subsubsection{Uncertainty expressed by counselees}

Counselees verbally revealed uncertainty as a spontaneous expression, as a response to a question or comment made by the counselor, and/or in the form of questions. Among their uncertain expressions, three distinct sources of uncertainty were identified: unpredictability of the future, lack of knowledge, 
and amount and complexity of information (Fig. 1). Uncertainty caused by unpredictability of the future (i.e., probability) was expressed by counselees about two issues: I) carrying a mutation and II) developing cancer (Table 3 citations IVa and IVb, respectively).

Another source of uncertainty expressed in these consultations related to counselees' personal lack of knowledge. Counselees' lack of knowledge pertained to multiple issues, the first of which was their family history of familial diseases and the cause of death of their relatives (Va). A second topic to which counselees' lack of knowledge pertained was the inheritance of mutations (Vb). Finally, counselees' uncertainty about their own lack of knowledge was related to practical procedures, e.g. how long it would take before they would receive the test results, or the location where their blood had to be sampled (Vc).

A third source of uncertainty expressed by counselees was labelled as the amount and complexity of information provided during consultation. This uncertainty was expressed in relation to their ability to understand and remember information and explain it to their relatives (VIa).

\section{Discussion and conclusion}

\subsection{Discussion}

This study explored uncertainties expressed within initial cancer genetic consultations. The results provide insight as to whether clinical practice underpins the conceptual literature on uncertainty; moreover, the results are relevant to further elucidate how uncertainty can be communicated to counselees such that it helps them to make appropriate decisions and cope with the implications of those decisions. The acquired data enabled to distinguish: i) what causes the uncertainty, ii) the topic to which the uncertainty pertains, and iii) the person experiencing the uncertainty; this is fully in line with (respectively) the source, the issue and the locus of uncertainty as defined in the conceptual models of Han et al. [7, 14]. Although their taxonomy was not used as a starting point for the present analysis, its structure emerged while coding the verbal expressions of uncertainty. Apparently, the basic structure of the taxonomy of Han and colleagues is an accurate reflection of the uncertainties expressed in genetic counseling, as it allows a useful distinction to be made between the cause and the content of uncertainty. 
Regarding the sources of uncertainty, the uncertainty expressed by both counselors and counselees mainly resulted from the unpredictability of the future and from lack of knowledge. Counselees also expressed uncertainty caused by the amount and complexity of information. The issues to which expressions of uncertainty pertained varied between the two groups, i.e. counselors expressed uncertainty mainly about scientific issues whereas the counselees' expressions mainly concerned personal and practical issues (Fig. 1).

In the present study, all sources of uncertainty could be classified within the conceptual taxonomy of Han et al. [7]. Conforming to the taxonomy, we found uncertainty to be caused by probability (i.e., unpredictability of future events), ambiguity (e.g., lack of knowledge), and complexity. In addition, Han et al. specified multiple other ways in which information can be ambiguous such as test limitations and test misinterpretations [14]. However, these additional and more specific forms of ambiguity were not encountered in the present study, probably due to the setting and the methodology used. We audiotaped consultations mainly involving the discussion of single gene tests, i.e., tests including a few genes associated with cancer. In contrast, Han et al. applied the original taxonomy to clinical genome sequencing [14]. This latter setting, where a multitude of genes are tested simultaneously, may involve a richer presentation of uncertainties (e.g. identifying an unsolicited mutation). Specific uncertainties related to multigene panel testing might not have emerged among our participants and, therefore, not expressed in the setting we investigated [14]. Additionally, we identified uncertainty on the basis of verbal expressions; counselors and counselees may have experienced additional uncertainties without actually verbalizing these during the consultations. It would therefore be informative to investigate what uncertainties are expressed non-verbally, for example by performing studies in which counselors and counselees are interviewed or genetic consultations are videotaped to identify non-verbal uncertainties.

Differences were identified among counselors in the degree and type of uncertainty they expressed during consultations. For example, some counselors explicitly informed counselees about uncertainty regarding how to screen for cancer as a result of a lack of knowledge at the scientific level, whereas others did not express this type of uncertainty. This diversity might be due to differences in the types of counselors involved, i.e., the present study included clinical geneticists, genetic counselors and 
medical residents. In general, the duration of consultations with the clinical geneticists was relatively shorter, possibly allowing less discussion of uncertainties compared with the other two profession groups. Another explanation may be differences in counselor' characteristics, such as gender, tolerance of uncertainty and personal uncertainty [30,31]. A previous study, mainly including general practitioners and physicians specialized in internal medicine, showed that female physicians experience more stress from uncertainty. In addition, more work experience was associated with a reduced stress level caused by uncertainty [31]. Moreover, no univocal results on the effects of tolerance of uncertainty on communication have been reported [30,31]. It would be interesting to examine how uncertainty is experienced by counselors, and whether and how the communication of uncertainty is associated with counselor' characteristics, such as gender and tolerance of uncertainty.

Even though differences in information provision is comprehensible, it is not desirable that counselees receive different information. As most genetic consultations involve a decision on genetic testing, counselees need to be fully informed. We saw, for example, that counselors differed in providing information on the limits of genetic science. This information with respect to preventive options is, however, important for counselees when deciding about genetic testing [12, 13]. Preferably, counselees are informed in a more consistent way about relevant scientific uncertainties.

Another noteworthy aspect is the discrepancy found between counselors and counselees regarding the issues to which the uncertainties pertained. Counselors expressed uncertainty related mainly to scientific topics, whereas the counselees were mainly concerned with personal and practical topics. Relatively few verbal expressions of uncertainty regarding scientific issues by counselees may imply unawareness (or no full comprehension) of the extent of the scientific uncertainties associated with genetic testing. In addition, counselees did not express uncertainty related to the emotional consequences of a certain test result, e.g. feeling guilty towards their children. This is particularly surprising, as patients have been previously found to frequently express such emotionally laden uncertainties as cues pointing to their underlying emotions [32]. Considering the substantial emotional consequences of uncertainty related to the consequences of test results, one would have expected them relatively frequently. Again, counselees may not be aware of the possible emotional consequences, nor do they assess their own ability to deal with these consequences. Both uncertainties are, however, 
important to counselees when deciding about genetic testing, but also to be able to anticipate on test results and their consequences afterwards. This study showed that counselees not only have to deal with the scientific uncertainties as explained by the counselors, but also face personal and practical uncertainties. As a result, counselees might be unable to fully focus on the highly complex information about scientific uncertainties that are provided during the genetic counseling [33-35]. Counselors might help to address this problem by i) regularly summarizing the key points, ii) checking the counselee's understanding, and iii) constantly taking into account counselees' uncertainty. After their personal uncertainties have been addressed, the counselee might be better able to (cognitively) focus on the scientific information provided by the counselors.

\subsubsection{Strengths and limitations}

To our knowledge, this is the first study to investigate the actuality of communicating about uncertainty during cancer genetic counseling. Audiotaping enabled observation of actual verbal expressions, rather than depending on recall. Moreover, a diverse sample of counselors was included. However, because all were recruited from two university hospitals, variation may have been missed due to center-specific ways of practicing genetic counseling. In addition, due to practical reasons it was decided to select counselees consecutively; nevertheless, some counselors may have been selective regarding which consultations to audiotape.

Only one consultation was recorded in which a multigene panel test was discussed. Since it was not possible to record more of this type of consultation during data collection, the present findings might be limited with regard to actual practice, which increasingly involves multigene panel testing.

\subsection{Conclusion}

This qualitative study provides insight into the range of uncertainties expressed by counselors and counselees during initial cancer genetic consultations. A wide range of uncertainties was expressed by both groups and these were in line with the conceptual model of uncertainty proposed by Han et al. [7]. It was found that counselors differ from counselees in the degree and types of uncertainty that they express. Among counselees, the low prevalence of uncertainty related to scientific topics suggests that they may frequently be unaware of these uncertainties. 


\subsection{Practice implications}

The results of this study imply that counselees are not (fully) aware of scientific uncertainties. These uncertainties should be addressed during genetic counseling to increase its awareness and understanding. Also, counselees are not uniformly informed about uncertainties related to genetic testing. To enable informed decision making and prepare counselees for possible test results, counselors should completely inform them. Finally, a training for counselors on how to manage and communicate these uncertainties may improve the communication in initial cancer genetic consultations.

\section{Conflict of interest}

All authors declare that they have no conflict of interest.

\section{Funding}

This work was funded by the Dutch Cancer Society (Grant no. UvA 2015-7607).

\section{Acknowledgements}

The authors thank all the counselors and counselees for their willingness to participate in this study.

This work was carried out for the purpose of the dissertation of N.M.

\section{References}

[1] R. Resta, B.B. Biesecker, R.L. Bennett, S. Blum, S.E. Hahn, M.N. Strecker, J.L. Williams, A new definition of genetic counseling: National Society of Genetic Counselors' task force report, Journal of genetic counseling 15(2) (2006) 77-83.

[2] J. Vos, F.H. Menko, J.C. Oosterwijk, C.J. Asperen, A.M. Stiggelbout, A. Tibben, Genetic counseling does not fulfill the counselees' need for certainty in hereditary breast/ovarian cancer families: an explorative assessment, Psycho-Oncology 22(5) (2013) 1167-1176.

[3] F. Van Zuuren, E. Van Schie, N. Van Baaren, Uncertainty in the information provided during genetic counseling, Patient education and counseling 32(1) (1997) 129-139.

[4] E. Bleiker, N. Aaronson, F. Menko, D. Hahn, C. Van Asperen, E. Rutgers, L. Ten Kate, N. Leschot, Genetic counseling for hereditary cancer: a pilot study on experiences of patients and family members, Patient education and counseling 32(1) (1997) 107-116.

[5] B. Meiser, J. Irle, E. Lobb, K. Barlow-Stewart, Assessment of the content and process of genetic counseling: a critical review of empirical studies, Journal of Genetic Counseling 17(5) (2008) 434-451. [6] J.E. Stopfer, Genetic counseling and clinical cancer genetics services, Seminars in Surgical Oncology, Wiley Online Library, 2000, pp. 347-357.

[7] P.K. Han, W.M. Klein, N.K. Arora, Varieties of uncertainty in health care: a conceptual taxonomy, Medical Decision Making 31(6) (2011) 828-838. 
[8] M.C. Politi, P.K. Han, N.F. Col, Communicating the uncertainty of harms and benefits of medical interventions, Medical Decision Making 27(5) (2007) 681-695.

[9] A.S. Babrow, C.R. Kasch, L.A. Ford, The many meanings of uncertainty in illness: Toward a systematic accounting, Health communication 10(1) (1998) 1-23.

[10] R. Lipshitz, O. Strauss, Coping with uncertainty: A naturalistic decision-making analysis, Organizational behavior and human decision processes 69(2) (1997) 149-163.

[11] E.G. Engelhardt, A.H. Pieterse, P.K. Han, N. van Duijn-Bakker, F. Cluitmans, E. Maartense, M.M. Bos, N.I. Weijl, C.J. Punt, P. Quarles van Ufford-Mannesse, Disclosing the Uncertainty Associated with Prognostic Estimates in Breast Cancer: Current Practices and Patients' Perceptions of Uncertainty, Medical Decision Making (2016) 0272989X16670639.

[12] R.T. Croyle, C. Lerman, Risk communication in genetic testing for cancer susceptibility, JNCl monographs 1999(25) (1999) 59-66.

[13] K.R. Blazer, B. Nehoray, I. Solomon, M. Niell-Swiller, J.O. Culver, G.C. Uman, J.N. Weitzel, NextGeneration Testing for Cancer Risk: Perceptions, Experiences, and Needs Among Early Adopters in Community Healthcare Settings, Genetic testing and molecular biomarkers 19(12) (2015) 657-665.

[14] P.K. Han, K.L. Umstead, B.A. Bernhardt, R.C. Green, S. Joffe, B. Koenig, I. Krantz, L.B. Waterston, L.G. Biesecker, B.B. Biesecker, A taxonomy of medical uncertainties in clinical genome sequencing, Genetics in medicine (2017).

[15] T.E. Quill, A.L. Suchman, Uncertainty and control: learning to live with medicine's limitations, (1993).

[16] M.G. Hewson, P.J. Kindy, J. Van Kirk, V.A. Gennis, R.P. Day, Strategies for managing uncertainty and complexity, Journal of general internal medicine 11(8) (1996) 481-485.

[17] D.S. Brody, The patient's role in clinical decision-making, Annals of Internal Medicine 93(5) (1980) 718-722.

[18] B.B. Johnson, P. Slovic, Presenting uncertainty in health risk assessment: initial studies of its effects on risk perception and trust, Risk analysis 15(4) (1995) 485-494.

[19] M.B. Walker, The relative importance of verbal and nonverbal cues in the expression of confidence, Australian Journal of Psychology 29(1) (1977) 45-57.

[20] C. Maslow, K. Yoselson, H. London, Persuasiveness of confidence expressed via language and body language, British Journal of Social and Clinical Psychology 10(3) (1971) 234-240.

[21] M.H. Mishel, Adjusting the fit: Development of uncertainty scales for specific clinical populations, Western Journal of Nursing Research 5(4) (1983) 355-370.

[22] J. Kasper, F. Geiger, S. Freiberger, A. Schmidt, Decision-related uncertainties perceived by people with cancer-modelling the subject of shared decision making, Psycho-Oncology 17(1) (2008) 42-48.

[23] H.C. Howard, E. Iwarsson, Mapping uncertainty in genomics, Journal of Risk Research (2017) 112.

[24] G.H. Gordon, S.K. Joos, J. Byrne, Physician expressions of uncertainty during patient encounters, Patient education and counseling 40(1) (2000) 59-65.

[25] J.J. Francis, M. Johnston, C. Robertson, L. Glidewell, V. Entwistle, M.P. Eccles, J.M. Grimshaw, What is an adequate sample size? Operationalising data saturation for theory-based interview studies, Psychology and Health 25(10) (2010) 1229-1245.

[26] J.M. Morse, The significance of saturation, Sage Publications Sage CA: Thousand Oaks, CA, 1995.

[27] MAXQDA, software for qualitative data analysis, 1989-2017, VERBI Software - Consult Sozialforschung $\mathrm{GmbH}$, Berlin, Germany.

[28] B.G. Glaser, A.L. Strauss, E. Strutzel, The discovery of grounded theory; strategies for qualitative research, Nursing research 17(4) (1968) 364.

[29] M. Murray, K. Chamberlain, Qualitative health psychology: Theories and methods, Sage1999.

[30] M.A. Hillen, C.M. Gutheil, T.D. Strout, E.M. Smets, P.K. Han, Tolerance of uncertainty: Conceptual analysis, integrative model, and implications for healthcare, Social Science \& Medicine 180 (2017) 6275.

[31] M.S. Gerrity, R.F. DeVellis, J.A. Earp, Physicians' reactions to uncertainty in patient care: a new measure and new insights, Medical care (1990) 724-736. 
[32] L. Heyn, C.M. Ruland, A. Finset, Effects of an interactive tailored patient assessment tool on eliciting and responding to cancer patients' cues and concerns in clinical consultations with physicians and nurses, Patient education and Counseling 86(2) (2012) 158-165.

[33] A.D. Lanie, T.E. Jayaratne, J.P. Sheldon, S.L. Kardia, E.S. Anderson, M. Feldbaum, E.M. Petty, Exploring the public understanding of basic genetic concepts, Journal of genetic counseling 13(4) (2004) 305-320.

[34] N. Hallowell, H. Statham, F. Murton, Women's understanding of their risk of developing breast/ovarian cancer before and after genetic counseling, Journal of Genetic Counseling 7(4) (1998) 345-364.

[35] J.L. Bottorff, P.A. Ratner, J.L. Johnson, C.Y. Lovato, S.A. Joab, Communicating cancer risk information: the challenges of uncertainty, Patient Educ Couns 33(1) (1998) 67-81. 
Figure 1. Overview of loci, sources and issues of uncertainty identified in the current study.

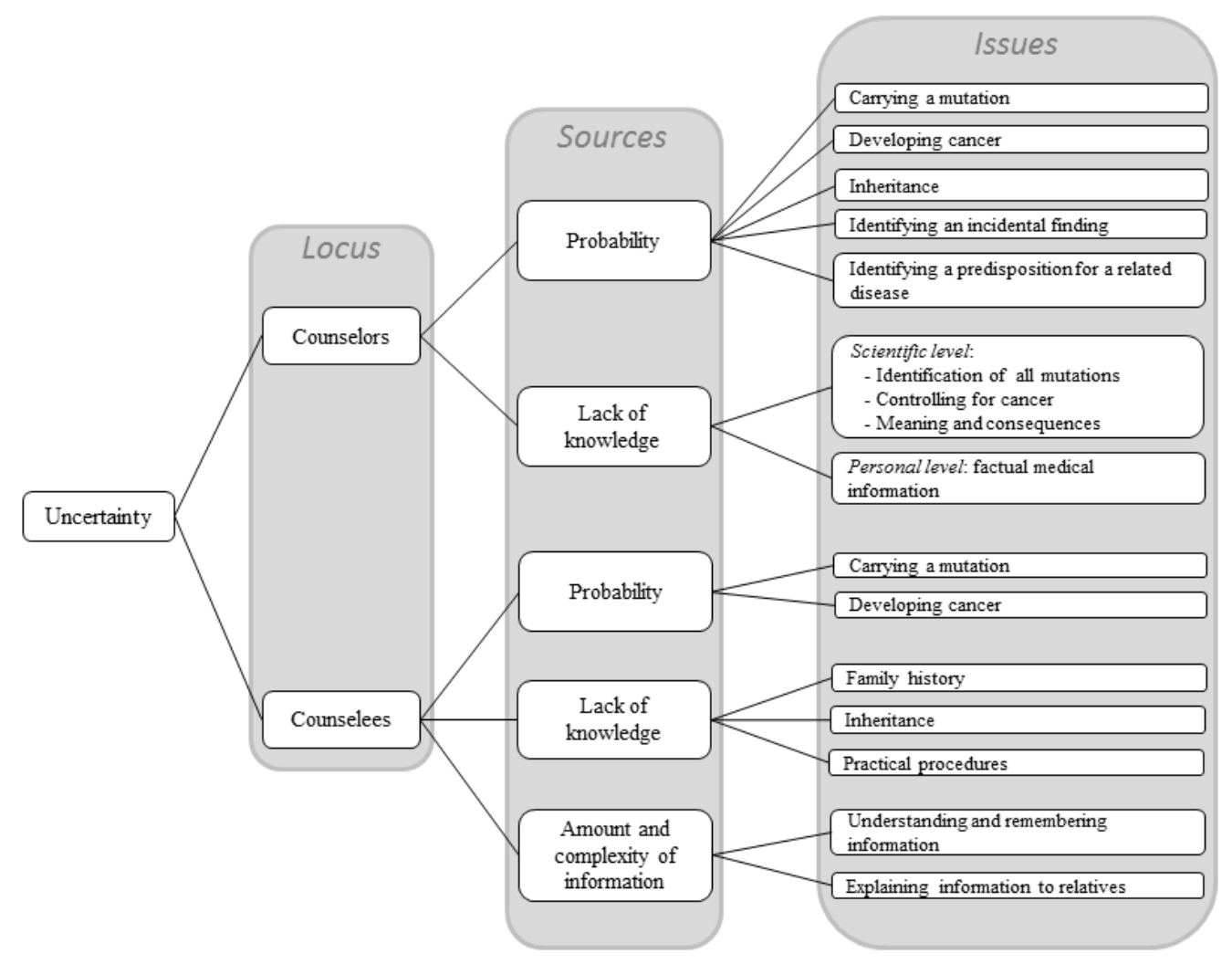


$\underline{\text { Table 1. Characteristics of the participating counselors and counselees. }}$

\section{n (\%)}

\begin{tabular}{|c|c|}
\hline Counselors (n=9) & \\
\hline Age in years: mean $\pm \mathrm{SD}$ (range) & $42 \pm 12(27-61)$ \\
\hline Sex & \\
\hline Male & $4(44)$ \\
\hline Female & $5(56)$ \\
\hline Professional training & \\
\hline Clinical geneticist & $4(44)$ \\
\hline Genetic counsellor & $1(12)$ \\
\hline Resident & $4(44)$ \\
\hline Work experience in years: mean $\pm \mathrm{SD}$ (range) & $9 \pm 9(0-22)$ \\
\hline Counselees $(n=25)$ & \\
\hline Age & \\
\hline $18-40$ years & $9(36)$ \\
\hline $41-65$ years & $10(40)$ \\
\hline$>65$ years & $6(24)$ \\
\hline Sex & \\
\hline Male & $5(20)$ \\
\hline Female & $20(80)$ \\
\hline Counselee type & \\
\hline Cancer patient & $14(56)$ \\
\hline Relative of cancer patient(s) & $11(44)$ \\
\hline Number of cancer types in the family & \\
\hline One & $17(68)$ \\
\hline Multiple (range 2-5) & $8(32)$ \\
\hline Cancer type in the family & \\
\hline Breast & $18(72)$ \\
\hline Pancreas & $4(16)$ \\
\hline Ovarium & $3(12)$ \\
\hline Colon & $3(12)$ \\
\hline Lymphatic & $2(8)$ \\
\hline Other types & $5(20)$ \\
\hline Genetic test & \\
\hline To be performed & $22(88)$ \\
\hline Not to be performed (yet) & $3(12)$ \\
\hline
\end{tabular}


Table 2. Verbatim examples of verbal expressions of uncertainty by counselors. 


\section{Counselors' expressions of uncertainty}

I Probability

Ia. of carrying a mutation:

"In 5 to $10 \%$ of cases cancer is hereditary, so only a small proportion of all cancers. The possibility that cancer is hereditary is slightly larger when the tumor is not hormone sensitive, or triple negative as we call it. You developed cancer at a later age so the chance that it's hereditary is smaller." (Counselor with 1 month of work experience)

Ib. of developing cancer:

"Based on our experiences, we can calculate the risk of developing breast cancer, which is about 20\%. We call that a moderately increased risk. To qualify as an increased risk, it must be over 30\% - in that case we start screening at a lower age. But the geneticist, with whom I have discussed this, thinks that this pedigree fits a moderate risk." (Counselor with 6 months of work experience)

Ic. of inheritance:

“Assuming your mother carried a hereditary predisposition which caused breast cancer, that would mean her first-degree relatives -her sisters, mother, brothers, children, daughters and son-have a 50\% chance to carry that same hereditary predisposition. So not in all cases ... but a 50\% chance. Heads or tails." (Counselor with 10 years of work experience)

Id. of identifying an incidental finding:

"The results can be: carrier, no carrier, a variant or an unexpected finding. To start with the last one, an unexpected finding means you find something you weren't primarily looking for but that can be of clinical relevance." (Counselor with 10 years of work experience)

Ie. of identifying a predisposition for a related disease:

"There are a few hereditary disorders that can sometimes cause pancreatic cancer: a certain type of hereditary breast cancer, an hereditary melanoma, or a malignant birthmark. And [pancreatic cancer] can also occur when someone carries a predisposition for hereditary colorectal cancer. " (Counselor with 22 years of work experience)

\section{$\underline{\text { II Lack of knowledge (scientific level) }}$}

IIa. about identifying mutations:

“When performing genetic testing in several women, we don't identify a clear hereditary cause in most. Does this mean there isn't a hereditary cause? Well we don't know for sure... because we as medical scientists don't know everything yet." (Counselor with 1 year of work experience)

"Sometimes we think there should be a predisposition, but we cannot find it. In those cases we know our techniques to test a gene are not $100 \%$ certain. They are quite good, but there is always a chance that a predisposition is present even though we didn't find it." (Counselors with 6 months of work experience) 
IIb. about how to control for cancer:

"You have a high chance of developing ovarian cancer. Depending on the gene, that chance is between 5 and 40\%. We cannot adequately screen for ovarian cancer, which means we cannot check the ovaries properly. We used to think that we could, but we can't." (Counselor with 17 years of work experience)

"You could check every six months, or every three months. But at some point you have to determine how we can prevent most cancers. When we screen every year, we avoid most cancers, but not all unfortunately." (Counselor with 1 year of work experience)

IIc. about the meaning and consequences of mutations:

"Sometimes we find a mutation and we don't really know what it means. We know the meaning of a lot of mutations and their consequences, but about some we just don't know everything yet." (Counselor with 6 months of work experience)

III Lack of knowledge (personal level)

IIIa. about factual medical information:

"I know that it's a very rare tumor and I know from the top of my head that it fits a hereditary disease in which people develop multiple polyps in the intestines. It's very rare, so I would have to figure out which syndrome this tumor fits, because I don't know that by heart." (Counselor with 10 years of work experience) 
Table 3. Verbatim examples of verbal expressions of uncertainty by counselees.

\section{Counselees' expressions of uncertainty}

\section{Probability}

IVa. of carrying a mutation:

Counselor: "Do you think you carry [the mutation] or not?"

Counselee: “Well, to me it's more a ratio... because I don't know... (32-year-old relative)

IVb. of developing cancer:

"I'm not afraid the [cancer] will recur. It will not recur, because it was not metastasized and the lymph node was clean, so that's not going to happen to me. But the chance that I'll develop it tomorrow is of course always present." (47-year-old cancer patient)

\section{$\underline{\text { V Lack of knowledge }}$}

Va. about family history:

Counselor: "At what age did your grandfather get prostate cancer and pancreatic cancer?"

Counselee: "I don't know when he got prostate cancer. He was 62 when he died, so I think 60 or 61."

Relative: "No, prostate cancer was at a younger age. He died at 62 and he had prostate cancer before that." Counselee: "I think somewhere in his late 50's, between 55 and 60.” (36-year-old relative)

Vb. about inheritance:

Counselee: "If I carry [a mutation], that doesn't necessarily mean I have it passed on?”

Counselor: "No. No, very good question." (46-year-old cancer patient)

"I am worried about my children, whether they carry something which causes them to develop cancer. I don't want that to happen to them." (57-year-old cancer patient)

Vc. about practical procedures:

Counselee: "How does this blood test work?"

Counselor: "You go all the way down and then you walk that way and there is the laboratory."

(58-year-old cancer patient)

$\underline{\text { VI Amount and complexity of information }}$

VIa. about understanding and remembering information and explaining information to relatives:

"Wait, could you repeat that? I'm not sure if I understood that correctly." (47-year-old cancer patient)

"Can I take a picture of that? That might help me explaining it to the boys." (42-year-old cancer patient) 